\title{
Does CVT of firms in Germany suffer from poaching?
}

Normann Mueller

\author{
Correspondence: normann.mueller@ \\ bibb.de \\ Federal Institute for Vocational \\ Education and Training, \\ Robert-Schuman-Platz 3, Bonn \\ 53175, Germany
}

\begin{abstract}
'Non-excludability' of skills is suspected to give rise to poaching externalities and cause under-investment in training. To substantiate this hypothesis, the paper at hand investigates the relationship between labor turnover and firms' dedication to continuing vocational training (CVT) exploiting novel survey data on firms in Germany (BIBB-FluCT data, $N=1.238$ ). Regression analyses of these data point at a negative correlation between turnover and CVT incidence in firms with presumably low skill needs (i.e. firms employing workers with no formal vocational education). However, the scope of the relationship is of limited economic relevance. Merely a minority of firms states to actually forego CVT because of high turnover. Also, the direction of the relationship remains debatable; a reversed negative effect of training on turnover seems unlikely, but not impossible. Eventually, when exclusively focusing on firms providing some CVT (80.6\% of the sampled firms), no negative and significant relationship between turnover and CVT spending emerges in the analyses; this is regardless of whether training is rather specific, or rather general. Overall, these findings do not serve to reinforce the notion of a generally detrimental effect of turnover on CVT. Note however, that a poaching problem may not necessarily become manifest in the relationship between turnover and training. For instance, employers explicitly stating to pay attention to potential training externalities provide CVT with a slightly lower probability than other employers. They might fear a free-rider problem regardless of the actual dimension of turnover. Notwithstanding, even this effect is limited in scope suggesting that only few firms actually withdraw from CVT because of a perceived free-rider problem. Altogether, the evidence available to substantiate the hypothesis of prevalent under-investment in CVT is not very compelling. In fact, payback clauses may help employers turn 'non-excludable' skills into part-time private goods and mitigate potential poaching risks. The analyses indicate that payback clauses go along with considerably higher employer-spending on CVT.

JEL codes: 122; J24; D61

Keywords: Poaching externalities, Continuing vocational training, Employer-provided training, Market imperfections, Human capital, Training finance, Private-sector training, Labor turnover
\end{abstract}

\section{Background}

The debate on training investment has continued for as long as a century by now. Triggered by the work of Pigou (1912) it has centered on the question of whether there is under-investment in training or not (see Leuven (2005) for a summary of the debate). Pigou's argument was that training investment yields external economies to outside firms as a consequence of workers changing employers or of firms poaching workers from

\section{Springer}

(c) 2014 Mueller; licensee Springer. This is an open access article distributed under the terms of the Creative Commons Attribution License (http://creativecommons.org/licenses/by/2.0), which permits unrestricted use, distribution, and reproduction in any medium, provided the original work is properly cited. 
other firms. Although a vast number of articles regarding the issue has been published during the century, probably the most influential contributions to the debate following Pigou were made in the 1960s by Gary Becker (1962) and in the 1990s by Stevens (1994, 1996) and Acemoglu and Pischke (1997, 1999a, b). Becker (1962), by distinguishing general and specific types of training with firms investing in specific and workers investing in general training, asserted that there could not be inefficiencies in training investment in competitive markets. The literature of the 1990s, however, basically questions the validity of this differentiation and argues that poaching externalities exist, if training is not strictly general or specific. The reasoning is that certain market characteristics may prevent workers from gaining the full return on general training investment and therefore provide an incentive to invest in general training for firms, too. It is further argued that in the presence of labor turnover, outside firms may benefit from investment in such training. These benefits are thought of as externalities, which are not taken into account by the investing firms. Hence, employer-investment levels in vocational training are allegedly suboptimal ${ }^{a}$. This argument has implications for the design of training policies. It provides a case for the implementation of training levies (Stevens 2001; Greenhalgh 2002; Kamphuis et al. 2010; Bosch 2012). The latter intend to overcome potential underinvestment by requiring employers to make contributions to trainings funds, out of which specific types of training can be financed.

Given these thoughts, it seems obvious that there is not only an academic interest of researchers in labor market economics but also an interest of policy makers in empirical research that helps assess the extent of underinvestment in employer-provided training. According to the OECD, the "identification of market failure could provide an additional input into a debate on [...] lifelong learning" (OECD 2004, p46). A few attempts have been made to approach the underinvestment hypothesis empirically (e.g. Feuer et al. 1987; Brunello and Gambarotto 2004; Brunello and De Paola 2008; Brunello and De Paola 2009; Muehlemann and Wolter 2011). However, no unambiguous message can be derived from these studies to date.

The paper at hand adds to this literature. It explores the relationship between the risk of employees leaving the firm and firms' commitment to continuing vocational training $(\mathrm{CVT})^{\mathrm{b}}$. For this purpose, it exploits a survey conducted in 2011 among 1.238 firms with at least 5 employees in Germany (BIBB-FluCT survey). In this survey, employers gave details pertaining to their investment in continuing training as well as labor turnover in their firm. Additionally, they provided geographical information that can be utilized to ensure that a potential relationship between training and turnover is independent of local market conditions.

In the following, I first lay out the theoretical background and erect testable propositions. Then, I review the available evidence and discuss the methodology for empirical testing, before I actually present and discuss the results of my analyses. I finally conclude by wrapping up, putting the results into perspective and pointing at further research needs.

\section{Methods}

\section{Propositions}

Even though this study focuses on continuing training, the theoretical underpinning of the under-investment hypothesis applies to initial training as well. The economic 
literature has concentrated much on the case of so-called ,poaching externalities'. Essentially, it is put forward that the amount of training provided by the market might be too low, because training investment could yield returns to outside firms, if employees chose to change employers after having received training.

This view is in contrast to the human capital theory (HCT) (Becker 1962) which argues that any training can be regarded as either firm-specific (i.e. of no use in other firms), or general (i.e. of use in many other firms), and proclaims that inefficiencies in training investment do not exist. According to HCT, in perfect labor markets workers would generally incur investments in general training, because they could reap the return in the form of market wages fully reflecting the increase in productivity due to training. There would be no rent accruing to the employer-side and, hence, no externalities in case of labor turnover. In contrast, specific investments are in principle undertaken by employers according to HCT. However, as separation of workers and employers after specific training would be associated with a loss for the investing firm, Becker (1962) predicts the latter to share costs and returns with trainees in order to safeguard against potential turnover.

In the 1990ies, Acemoglu and Pischke (1999a, 1999b) put forward that due to labor market frictions, workers' market wages may not rise as high as their productivity after having pursued general training activities. As a consequence of such 'wage compression', part of the returns to training would accrue to the firms employing the workers after their training, thereby making the training de facto at least partly specific. Thus, the existence of such a rent would create an incentive for firms to invest in training that is useful in many outside firms, too. Contrasting HCT, Acemoglu and Pischke (1999b) hold that such training yields externalities, because it is not truly specific, but merely de facto specific and technologically general, meaning that in case of separation future employers may benefit from the investment. Acemoglu (1997) explains that workers may anticipate that part of the "productivity gains [...] will be captured [...] by future employers" ( $\mathrm{p} 460)$, providing a disincentive to invest in general training when it is at least partly de facto specific. As a consequence of Acemoglu's argument, one ought to expect worker's disincentive to disrupt the sharing-mechanism. Hence, employer investment should suffer from this, too. In line with this, Acemoglu (1997, p453-454) predicts an inverse relationship between labor turnover, which measures the likelihood of outside firms benefitting from training investments, and training.

Quite similar, Stevens (1994) argues that firms may invest not only in purely specific skills. In her model, firm heterogeneity creates an investment incentive for employers, because training is of different use across firms and employers can pay wages below workers' productivity in their firm. However, there is a chance that workers leave the firm, if the training they received at this firm is of greater value to an outside employer. When workers and employers separate after training, this rent according to Stevens is an externality to outside firms. Hence, too few workers will be trained given the total social return. The more firms there are in the market, the lower the wage cut a firm can impose on trained workers and the lower will be the resulting externality, even though the likelihood for workers ending up with different employers after training is high. Also, the externality is lower the more pronounced the specific element of training is.

Two assumptions are essential for the emergence of externalities in the models of Acemoglu and Pischke (1999a, b) and Stevens (1994, 1996). In specific, both assume 
that there is an incentive for firms to invest in general or transferable skills in the first place. It is given by market imperfections like wage compression or firm heterogeneity, which create a gap between worker wages and productivity levels (and thus a rent for firms). Additionally, there must be a risk of turnover. That is, the probability of workers staying with the firm or leaving it after training must not be equal to zero or one. So, according to Acemoglu and Pischke and Stevens, externalities arise as a consequence of market imperfections in combination with turnover.

Note that the poaching hypothesis is relevant only to skills that are of use in other firms, too, and not purely specific to the investing firm. This is probably the reason why many authors in political consulting prefer to interpret the problem in the sense of a collective goods issue. According to this view, vocational skills are a common-pool resource. Skills inherent in a person are ,non-excludable' in the way that any employer may hire the owner of such skills regardless of whether his or her company has financially contributed to skill development or not. Non-excludability in turn may bring along a free-rider problem with employers opting "to buy in skilled labour rather than investing in training" themselves, leading to collectively suboptimal levels of training investment (OECD 2003, p125; Kamphuis et al. 2010, p274-275).

This argument consequently provides a case for the implementation of training levies (Stevens 2001; Greenhalgh 2002; Kamphuis et al. 2010; Bosch 2012), which intend to overcome potential collective underinvestment. Essentially, levy schemes require employers to make a payment (which is most often based on payroll size) to training funds with sectoral or national coverage. These funds are then used to finance specified types of training. The debate on levy schemes illustrates that there is not only an academic interest, but also a great political interest in studies attempting an assessment of how relevant under-investment because of poaching is in reality.

To allow for such an assessment, it is necessary to derive from the previous discussion propositions that can be tested empirically. Given the prevailing view of poaching externalities and under-investment existing as a consequence of market imperfections in combination with turnover, the following proposition should hold.

\section{Proposition 1: Turnover has a negative impact on the incidence of and investment in employer-provided training - given the market conditions.}

An empirical analysis must control for the market conditions, because they may influence the investment incentive for firms and simultaneously affect turnover rates. So, if the analysis did not take account of that, turnover rates might capture the effect of market conditions. A negative relationship between employer-provided training and turnover then might merely indicate that firms' investment incentives are reduced in more efficient labor markets, because the rents from wage compression or firm heterogeneity vanish. Hence, the computed effect could not necessarily be interpreted as evidence in favor of under-investment. In the first place, it would hint at market imperfections rendering general skills de facto specific and market conditions being an important determinant of how the costs of training are shared between employers and workers. As long as workers compensated for reductions in employer spending associated with more efficient labor markets, there would not be under-investment. Diagnosing under-investment is possible only, if turnover affects employer-provided training independent of market conditions. 
Further on, remind that firms-specific training is not subject to poaching hazards. Nevertheless, if there is a high exogenous risk of workers leaving the firm after training, employers may cut back investment in specific skills, too. So, there may be a negative relationship even for specific training investment. However, according to the sharingargument made by Becker (1962) and formalized by Hashimoto (1981) for the case of specific skills, the sharing of costs and returns may just serve to internalize the risk of turnover and prevent investment inefficiency. So, Proposition 1 is not sufficient to diagnose under-investment. Additionally, the effect stated in Proposition 1 should be stronger for transferable skills than for specific skills. If it was the same for both types of skills, one might argue that the observed general or transferable training is de facto specific and that the measured effect is just the one implicated by the sharing-argument.

Proposition 2: The effect of turnover of employer-provided training is stronger in the case of predominantly general training contents than in the case of predominantly specific training contents.

\section{Challenges in empirical testing}

In the sphere of politics and political consulting it is sometimes suggested that underinvestment could be asserted by comparing training levels internationally. Of course, this approach falls far short, because optimal training levels are determined by the very complex institutional settings in countries' education and labor markets. The latter, however, may vary drastically between countries. Further, it is not sufficient to show that government subsidies or other assistance actually stimulate training levels, because this could be the case, even if investment was already optimal in absence of the support. Finally, it has been suggested that market failure could be substantiated by demonstrating that private training returns are relatively high in comparison to training incidence, social returns to training, or other investments. All these approaches, however, are inadequate as relatively high returns are compatible with investment efficiency if marginal costs are high (see Brunello and De Paola 2009 for a more thorough discussion of empirical evidence on under-provision of training). Instead, it is necessary to look at the relationship between turnover and training investment as the previous discussion of the theoretical literature has clarified.

It should be noted, however, that ideally one should look at total training investment, including both the contributions of firms and the contributions of workers. This is, because both parties may share the costs of training; and turnover rates may determine nothing but the size of the shares, if they merely capture market conditions. A negative relationship between turnover and employer-provided training would then not automatically hint at under-investment (see discussion in chapter 2). However, employeremployee data are costly and hardly available. Additionally, the political debate on levy schemes as a potential solution to the under-investment problem pays attention primarily to the employer-side implying that a free-rider problem exists between firms. For these reasons the focus in this paper is on the employer-side. One should keep in mind, however, that any diagnostics based on regression analyses come with the reservation of successful control of market conditions.

Moreover, determining the direction of causality is a major challenge when examining the relationship between turnover and training. This is, because turnover may not only be a potential determinant of employer-provided training; it may itself be influenced by 
firms' training behavior (see Brunello and De Paola 2009). The provision of training for employees may help strengthen their bond with the company. Hence, the presence of a negative relationship cannot indicate what is cause and effect. Results thus need to be treated with caution when a solution of the reversed causality problem is impossible ${ }^{c}$.

\section{Existing empiricial studies}

Some empirical studies have looked at the relationship between turnover and employer-investment in training using individual data. As early as 1987, Feuer et al. (1987) have focused on the influence of training on the probability of worker turnover. With the help of individual data for the US from the 1972-1978 National Survey Natural and Social Scientists and Engineers (NSSE), they detect a negative correlation between employer contributions to post-BA college-based education and the probability of turnover. However, they note that causality remains moot. Krueger and Rouse (1998) examine individual participation in a publicly subsidized, but employer-based training program offered at two mid-sized manufacturing firms in New Jersey. Employer contributions in this program covered indirect cost only (i. e. foregone cost of production due to personnel absence). The authors find a small negative, but not significant effect of training participation on the probability of employees leaving the company after training. They do, however, point at the possibility of an inverted relationship. Similarly, Zweimueller and Winter-Ebmer (2003) based on Swiss labor force data find evidence that employer-provided training is associated with reduced job search and quit behavior of workers. However, the analysis cannot rule out that workers searching for job more actively or obviously may receive less training because of the threat of poaching. A recent study by Brunello and De Paola (2009) safeguards more effectively against causality issues. Using individual data from the European Community Household Panel (ECHP) and applying a time lag of one to three periods to their training variable, the authors find some evidence in favor of employer-provided training reducing the probability of individual turnover one to three years after training. Based on this evidence, Brunello and De Paola (2009) conclude that investment efficiency cannot be ruled out ${ }^{\mathrm{d}}$.

Other studies based on firm-level data have examined the impact of regional economic density on employer-provided training. Muehlemann and Wolter $(2006,2011)$ with the help of survey data on firms in Switzerland find that a higher number of firms in a region deteriorates employers' investment in initial training. Similarly, Brunello and De Paola (2008) based on a sample of Italian manufacturing firms with 10 to 500 employees find that the number of employees per squared kilometer is negatively related to the percentage of employees trained by their employers in Italian provinces. Both studies find that a 10 percent increase in their measure of economic density reduces workers' probability of being trained by 1-2 percent, a small effect, but not negligible. Brunello and de Paola attribute their finding to the potentially higher risk of poaching in economically more dense areas. Brunello and Gambarotto (2004) exploiting individual data for the UK use the same measure of economic density and find even stronger effects on employer-provided training.

While these studies provide enormously valuable insights into the role of geography for enterprise training, their results do not necessarily substantiate market failure (also see Brunello and De Paola 2008, p137). As discussed previously, with fewer firms in the market, monopsony power of employers in turn may increase. Market conditions, 
however, determine whether skills are of general or de facto specific character. A reduction in the number of outside options gives rise to additional investment incentives for employers. Yet, this mechanism does not imperatively contradict human capital theory, which explicitly allows for market conditions to change the character of training such that firms dare to invest in the development of technologically general skills (see Becker 1962, p24ff). To assess investment efficiency, estimation models need to simultaneously consider market conditions (including geographical aspects) as well as turnover rates. Also, the effect of turnover on investment in transferable skills should be distinguished from its effect on investment in specific skills. Apart from that, geographical differences may go along with different training attitudes of employers. However, if a negative relationship merely reflected preferential differences, it would not indicate inefficiency.

Few studies have actually investigated the influence of labor turnover on the probability or intensity of employer-provided training. Often, these studies explore multiple determinants of training incidence and pay attention to the effect of turnover only cursorily. Market failure is typically not debated in depth and causality issues are not treated in those studies. For instance, Lynch and Black (1998), based on firm-level data for the US, measure the risk of turnover using the percentage of employees who have worked in a firm for less than one year ${ }^{\mathrm{e}}$. They detect a small deteriorating effect on the incidence of employer-provided training. The effect vanishes, however, when the proportion of trained workers is used as the dependent variable. Similarly, Neubaeumer et al. (2006) with the help of German establishment data find no relationship between turnover and firms' dedication to continuing vocational training.

In summary, existing empirical studies do not yet deliver an unambiguous and robust message concerning the practical relevance of market failure due to poaching. This is partly because of methodological differences (e.g. different model specifications, data sources, data coverage, estimation procedures, concepts of operationalization etc.) and partly because of the unexplained causal direction concerning the relationship between explanatory and dependent variables. The goal of the analyses presented in this paper has been to contribute to this literature by separating the influence of market conditions from the influence of poaching and addressing causality issues.

\section{Data}

For the purpose of empirically testing the previously stated propositions, the Federal Institute of Vocational Education and Training (BIBB) conducted in the year 2011 a survey among 1.238 firms in Germany with at least 5 employees (BIBB-FluCT survey 2011; Mueller 2013b). During a half-hour computer-assisted telephone interview (CATI), the company management (35\%), representatives from human resources departments (60\%), or other knowledgeable staff members (5\%) were asked for information on the firm's CVT philosophy and organization, its formal CVT exposure (excluding informal training), the reasons for financing or not financing CVT, the transferability of CVT, and the extent of labor turnover, in the reference year $2010^{\mathrm{g}}$. Apart from these aspects, the questionnaire covered various other company characteristics, such as the economic performance, innovativeness, or the role of unions and work councils. Also, the interviewees gave details on the geographical location of their establishment. For instance, the dataset includes the distance of an establishment from some 14 predefined metropolitan areas in Germany (all German cities with at least 
500.000 inhabitants), the population figures for the largest city in less than 45 minutes distance travelling by car or train, and information on the presence of an industrial agglomeration. These geographical details are of interest, because they may help control market conditions. Obviously, no information is available on the financial contributions of employees to CVT in the surveyed firms.

Random sampling was based on a simple one-stage procedure. However, it has been the goal to obtain valid results for large companies as well as smaller companies. Hence, the sample had to be stratified disproportionately such that large and medium companies were over-represented in the sample compared with their frequency in the population. For the same reason, firms from East Germany were selected into the sample with a higher probability. To account for stratification and varying response rates across firms of different size and from different regions, the data have been fitted to the marginal distributions of firm size (5-9, 10-49, 50-249, at least 250 employees) and region (North Germany, South Germany, North Rhine-Westphalia, East Germany) by applying the respective adjustment weights ${ }^{\mathrm{h}}$.

Altogether, the rate of response in the survey was $11.6 \%$; this relatively low magnitude must probably be attributed to the complexity of the survey design, and it brings up selectivity concerns. In specific, it is possible that firms with an interest in CVT participated in the survey with a higher-than-average probability leading to distorted estimates of population parameters (such as for instance CVT incidence). However, the purpose of this paper is the estimation of the relationship between population parameters via regression analyses, and not the estimation of population parameters themselves. So, potential selectivity of the sample with respect to CVT affinity is not a serious issue; at least as long as there is a sufficient number of firms with few or no CVT activities in the sample to perform multivariate analyses. If anything, a problem could arise, if there was selectivity with regard to the relationship between turnover and CVT, for instance because firms with an exceptionally high or low sensitivity to the risk of poaching participated more frequently in the survey than others. Given, however, that the exact purpose and topic of the survey were unknown to the firms when admitting the interview, it seems unlikely that this type of selectivity is a relevant problem for the analyses.

\section{Empirical models and estimation procedure}

To test whether turnover affects firms' dedication to CVT, two different empirical models were applied to two different (sub-)samples of the BIBB-FluCT data, the full sample on the one hand, and the subsample of training firms on the other. The first model investigates for the full sample the effect of turnover on the incidence of employer-provided CVT:

$$
\ln \frac{P\left(c t_{-} y n=1\right)}{P\left(c t \_y n=0\right)}=\alpha+\boldsymbol{\beta} \times \boldsymbol{f l u c t}+\boldsymbol{\gamma} \times \text { market }+\boldsymbol{\delta} \times \text { skill_need }+\boldsymbol{\theta} \times \boldsymbol{H R}+\boldsymbol{\varepsilon}
$$

In equation (1), ct_yn (CVT incidence) is binary. It takes on the value 1, if the observed firm had contributed directly to the financing of CVT for employees in at least one case during 2010 regardless of scope $(81.2 \%$ of the firms in the sample, not weighted), and 0 otherwise ${ }^{\mathrm{i}}$. This model was estimated via logistics regression (Logit). 
The second model looks at training firms only. It examines the effect of turnover on the scope of employers' CVT spending per worker, ct_inv, measured as the log of total direct expenditures for CVT in the year 2010, divided by the number of employees at the due date. The weighted average of CVT spending per worker is 272 Euro $^{j}$.

$$
\log (\text { ct_inv })=\alpha+\boldsymbol{\beta} \times \text { fluct }+\gamma \times \text { market }+\boldsymbol{\delta} \times \text { skill_need }+\boldsymbol{\theta} \times \boldsymbol{H R}+\boldsymbol{\varepsilon}
$$

This measure does not include personnel absence cost, i.e. the value of employees' foregone productive contribution. Equation (2) has been estimated via the method of ordinary least squares (OLS) for both (sub-)samples ${ }^{\mathrm{k}}$.

The right-hand sides of both equations contain the explanatory variables ${ }^{1}$. fluct is a vector encompassing two different turnover rates. Turnover rate 1 is the one relevant for investigating poaching issues. It relates to the departure of workers who were principally disposable for other firms after separation, i.e. dismissals/quits and the expiration of temporary work contracts, which account for roughly two thirds of all turnover. The weighted average in the sample is 9.0\% (firms with 5-9 employees: 9.8\%; firms with 10-49 employees: 8.5\%; firms with 50-249 employees: 7.7\%; firms with at least 250 employees: 7.8\%). The second measure of fluctuation (turnover rate 2) is of subordinate interest. It subsumes departures of workers who could not be employed by other firms after separation, for instance because of retirement or occupational disability. Both turnover rates give the number of employees who left the establishment during 2010 related to the total number of workers employed by the observed firm at a given reference date in $2010^{\mathrm{m}}$.

The vector market includes some variables that ought to control for market conditions determining the degree to which technologically general skills might be turned into de facto specific skills. It contains

- a full set of region controls (16 dummy variables indicating affiliation with German Bundesländer),

- a full set of industry controls (21 dummy variable),

- a measure of the travel distance to metropolitan areas $(0=$ up to $50 \mathrm{~km}, 1=$ more than $50 \mathrm{~km}),{ }^{\mathrm{n}}$

- a variable capturing the presence of an industrial agglomeration (i.e. many firms of the same industry in the region) $(0=$ no, $1=$ yes $)$, and

- a set of binary variables for the firm size (5-9, 10-49, 50-249, 250 or more employees)

Further on, the right-hand side incorporates variables in the vector skill_need that are intended to control for firms' skill needs. These variables mirror on a rough level the development of demands on the workers $(-1=$ decreasing, $0=$ stable, $1=$ increasing $)$, the presence of $R+D$ activities in the company $(1=$ yes, $0=$ no), and the intensity of firms' innovativeness $(1=$ high, $0=$ low $)$. Also, a measure of the qualification structure ( 1 = employment workers without formal vocational qualification, $0=$ no employment of workers without formal qualification) is included in the estimates. Eventually, when estimating equation (2), the model considers a binary variable indicating whether training was predominantly specific to the firm $(=1)$ or transferable to other firms, too $(=0)$. To measure the degree of specificity, the interviewees were asked to state whether "rather 
few" or "most" of the skills developed during employer-financed training could be of use in other firms, too. Respondents had to decide between these two alternatives.

Finally, some variables are considered that proxy for various aspects of HR policy as the latter might simultaneously contribute to high CVT commitment and low labor turnover. On the one hand, there are exogenous aspects that cannot be influenced by the firm in connection with decisions on CVT activities. These are the presence of collective labor agreements $(1 / 0)$, and the existence of work councils $(1 / 0)$. On the other hand, there are aspects that are highly endogenous because they can indeed be influenced by the firm in connection with the decision on CVT activities. These are the presence of formal agreements between employer and worker representation (e.g. work councils) relating to CVT (1/0), the degree of professionalization in CVT $(1=$ high, $0=$ low), the existence of payback clauses (1/0), and the receipt of financial aid from training funds based on levy schemes (1/0). All these aspects are represented in equation (2) by the vector $\boldsymbol{H R}$. Further on, this vector contains two variables indicating whether firm representatives stated in the interview that potential benefits to outside firms (externalities) and the general risk of turnover played a role for entrepreneurial training decisions $(1 / 0)^{\circ}$. Eventually, logged wage levels have been considered as explanatory variable in the model, as high wages may go along with a high scope of CVT activities to reduce turnover. Absolute wage levels were used instead of relative wage levels (compared to other firms in the same industry) as industry controls are included in the analyses as well. Note that the inclusion of endogenous covariates is not a serious problem, given that the relationship of these variables with turnover is not the focus of the analyses. Indeed, it makes sense to control for these aspects, because they may capture common variance in turnover and CVT that does not indicate a negative effect of turnover on training, but merely hints at training going along with an HR policy aimed at employee retention. If poaching actually causes under-investment in CVT, a negative relationship between turnover and CVT should be visible, even when the mentioned aspects of HR policy are controlled in the model.

The estimates were computed with the help of the statistical software Stata 12. Even though missing values account for less than $5 \%$ of the cases in most of the variables (less than $10 \%$ for turnover and employers' CVT spending), roughly $44 \%$ of the cases have missing values in at least one variable. This is primarily because many firms did not report wage information. There are almost $40 \%$ missing values in wage levels, which drastically reduces the number of observations available for regression analyses. To make use of the maximum number of observations, the analyses have been based on multiply imputed data ${ }^{\mathrm{p}}$. The estimates were performed with the help of Stata's class of - mi estimate - commands. These commands integrate into the regression analyses multiple realizations of a predefined imputation model and provide a single estimate for each model parameter. 20 imputations were computed for both Logit and OLS estimation. Tests, however, suggest that the results depend only marginally on the number of imputations. The imputation model incorporates all variables considered in the regression models ${ }^{\mathrm{q}}$.

\section{Interaction effects}

As an extension of the basic models given by equations (1) and (2), interaction terms were included in the models to test whether the effect of turnover on employer- 
provided CVT varies between certain groups of firms. I considered the following moderator variables:

- firm size (differentiating between firms with more than 250 employees and smaller firms)

- qualification structure (employment of workers without formal vocational qualification)

- a binary variable taking on the value 1 if firm representatives find CVT to be a "very important" means of reducing turnover

Interactions of turnover with three additional moderator variables were tested exclusively in the OLS estimates, because the respective characteristics are relevant solely (or especially) for training firms:

- a binary variable indicating the degree of training specificity, and

- a binary variable indicating whether firms make use of payback clauses.

The interaction effect between turnover and the degree of training specificity is of special interest, as in the case of under-investment the effect of turnover on firms' CVT commitment is expected to be stronger for general or transferable training (proposition 2).

\section{Results and discussion}

\section{Turnover and CVT incidence}

The Logit estimates of equation (1) are displayed in Table 1. Column 1 displays the results from estimating a parsimonious specification with turnover rates as the only explanatory variables. Column 2 shows how the results change when market controls are included in the model. Column 3 illustrates the effect of including the measures indicating firms' skill needs as well as the variables indicating the existence of collective labor agreements and worker representation (exogenous aspects influencing human resources policies). Finally, column 4 demonstrates the impact of HR policy and firm representatives' attitudes with regard to CVT.

Most importantly, a negative coefficient is attached to the turnover variable capturing quits, dismissals, and the expiration of temporary work contracts. It is significant in all estimated specifications indicating a negative relationship between turnover and CVT incidence. As expected, there is no relationship between CVT incidence and turnover due to employees retiring or leaving the firm for reasons that prevent them from getting engaged with other employers (as reflected by turnover rate 2$)^{\mathrm{r}}$.

To investigate the relationship further, I included in the regression model an interaction term between turnover and qualification structure (employment of workers without formal vocational degree, see Table 1, column 5). The coefficient of turnover now reflects the relationship with CVT incidence for firms employing only formally qualified workers. It turns out non-significant and the odds ratio is equal to one implying that there is no relationship between turnover and CVT incidence in these firms. On the contrary, the odds ratio pertaining to the interaction term indicates a negative relationship for firms employing workers without formal 
Table 1 Logit estimation of CTV incidence

\begin{tabular}{|c|c|c|c|c|c|c|}
\hline Dependent variable: CVT incidence (0/1) & (1) & $(2)$ & (3) & (4) & (5) & (6) \\
\hline Turnover 1 (TO1) & $0.978^{* * *}$ & $0.983^{* * *}$ & $0.986^{* *}$ & $0.981^{* * *}$ & 1.000 & $0.977^{* * *}$ \\
\hline$(\ln \%)$ & $(0.005)$ & $(0.006)$ & $(0.006)$ & $(0.006)$ & $(0.012)$ & (0.008) \\
\hline Turnover 2 & 1.000 & 0.997 & 0.985 & 1.066 & 1.062 & 1.065 \\
\hline$(\ln \%)$ & $(0.019)$ & $(0.026)$ & $(0.026)$ & $(0.062)$ & $(0.061)$ & $(0.061)$ \\
\hline CVT to reduce turnover & & & & & & 1.661 \\
\hline (see Table notes) & & & & & & $(0.622)$ \\
\hline TO1 X CVT to reduce turnover & & & & & & 1.034 \\
\hline (Interaction term) & & & & & & $(0.0251)$ \\
\hline Collective labor agreement & & & 0.754 & 0.642 & 0.674 & 0.688 \\
\hline ( $0=$ no, $1=$ yes $)$ & & & $(0.187)$ & $(0.217)$ & $(0.225)$ & $(0.237)$ \\
\hline Worker representation & & & $1.916^{*}$ & 1.529 & 1.476 & 1.426 \\
\hline$(0=$ no, $1=$ yes $)$ & & & (0.690) & $(0.814)$ & $(0.785)$ & $(0.733)$ \\
\hline Innovativeness & & & 0,888 & 0.770 & 0.773 & 0.724 \\
\hline$(0=$ low, $1=$ high $)$ & & & $(0.214)$ & $(0.237)$ & $(0.239)$ & $(0.220)$ \\
\hline $\mathrm{R}+\mathrm{D}$ activities & & & 0.615 & 0.907 & 0.854 & 0.896 \\
\hline$(0=$ no, $1=$ yes $)$ & & & (0.194) & $(0.397)$ & (0.379) & $(0.405)$ \\
\hline Demands on workers & & & $0.489^{* * *}$ & $0.462^{* *}$ & $0.449^{* *}$ & $0.451^{* *}$ \\
\hline$(-1=$ increasing, $0=$ stable, $1=$ decreasing $)$ & & & $(0.125)$ & $(0.146)$ & $(0.143)$ & $(0.141)$ \\
\hline Qualification structure & & & $0.591^{* *}$ & $0.406^{* * *}$ & 0.574 & $0.418^{* *}$ \\
\hline$(1$ = employment of workers w/o degree, 0$)$ & & & $(0.151)$ & $(0.136)$ & $(0.224)$ & $(0.142)$ \\
\hline TO1 X qualification structure & & & & & $0.966^{* *}$ & \\
\hline (Interaction term) & & & & & $(0.0157)$ & \\
\hline Wages & & & & 1.007 & 1.058 & 0.998 \\
\hline (logged) & & & & $(0.322)$ & $(0.340)$ & $(0.317)$ \\
\hline CVT professionalism & & & & $2.230^{* *}$ & $2.262^{* *}$ & $2.004^{* *}$ \\
\hline$(0=$ low, $1=$ high $)$ & & & & $(0.710)$ & $(0.725)$ & $(0.641)$ \\
\hline Training funds receipts & & & & $43.43^{* * *}$ & $50.13^{* * *}$ & $40.90^{* * *}$ \\
\hline$(0=$ no, $1=$ yes $)$ & & & & $(58.26)$ & $(68.11)$ & $(56.33)$ \\
\hline Payback clauses & & & & 1.626 & $1.678^{*}$ & 1.548 \\
\hline$(0=$ no, $1=$ yes $)$ & & & & $(0.503)$ & $(0.520)$ & $(0.482)$ \\
\hline CVT agreements & & & & 1.179 & 1.180 & 1.272 \\
\hline ( $0=$ no, $1=$ yes $)$ & & & & $(1.065)$ & $(1.062)$ & $(1.166)$ \\
\hline Recognition of externalities & & & & $0.478^{* *}$ & $0.466^{* *}$ & $0.465^{* *}$ \\
\hline (Self-reported; $0=$ no, $1=$ yes) & & & & $(0.172)$ & $(0.169)$ & $(0.172)$ \\
\hline Sensitivity to risk of turnover & & & & 1.120 & 1.119 & 1.095 \\
\hline (Self-reported; $0=$ no, $1=$ yes) & & & & $(0.340)$ & $(0.339)$ & $(0.332)$ \\
\hline Industrial agglomeration & & 0.974 & 1.155 & 1.664 & 1.643 & 1.712 \\
\hline$(0=$ no, $1=$ yes $)$ & & $(0.243)$ & (0.304) & $(0.588)$ & $(0.579)$ & $(0.615)$ \\
\hline Metropolitan distance & & $0.600^{* *}$ & $0.572^{* *}$ & 0.590 & $0.566^{*}$ & $0.561^{*}$ \\
\hline$(0=$ up to $50 \mathrm{~km}, 1=$ more than $50 \mathrm{~km})$ & & $(0.152)$ & $(0.150)$ & (0.194) & $(0.188)$ & $(0.185)$ \\
\hline \multicolumn{7}{|l|}{ Firm size (ref. 5-9 Besch.) } \\
\hline \multirow[t]{2}{*}{ 10-49 employees } & & 1.069 & 1.116 & 0.690 & 0.686 & 0.690 \\
\hline & & $(0.235)$ & $(0.253)$ & $(0.205)$ & $(0.205)$ & $(0.204)$ \\
\hline \multirow[t]{2}{*}{ 50-249 employees } & & $3.533^{* * *}$ & $3.375^{* * *}$ & $2.653^{* *}$ & $2.610^{*}$ & $2.613^{*}$ \\
\hline & & (1.078) & (1.183) & $(1.306)$ & $(1.320)$ & $(1.291)$ \\
\hline
\end{tabular}


Table 1 Logit estimation of CTV incidence (Continued)

\begin{tabular}{lllllll}
\hline 250 or more employees & & $7.910^{* * *}$ & $8.081^{* * *}$ & $3.824^{* *}$ & $3.921^{* *}$ & $4.007^{* *}$ \\
& & $(2.779)$ & $(3.708)$ & $(2.401)$ & $(2.514)$ & $(2.549)$ \\
\hline Industry controls & NO & YES & YES & YES & YES & YES \\
Region controls & NO & YES & YES & YES & YES & YES \\
\hline Constant & $3.434^{* * *}$ & 1.103 & 3.686 & 29.49 & 18.89 & 43.41 \\
& $(0.407)$ & $(0.949)$ & $(3.767)$ & $(104.8)$ & $(67.31)$ & $(154.8)$ \\
\hline $\mathrm{N}$ & 1,206 & 1,199 & 1,190 & 1,047 & 1047 & 1041 \\
Pseudo- $R^{2}$ & 0.024 & 0.135 & 0.161 & 0.228 & 0.235 & 0.243 \\
\hline
\end{tabular}

Notes: *** $\mathrm{p}<0.01, * * \mathrm{p}<0.05, * \mathrm{p}<0.1$.Multiply imputed data. Logit coefficients have been transformed to odds ratios. Reported $\mathrm{R}^{2}$ relates to the respective estimates based on a single imputation approach. Column 5 considers an interaction term between turnover rate 1 and qualification structure. Column 6 considers an interaction term between turnover rate 1 and a moderator variable, indicating whether the interviewed firm representatives regard CVT as a "very important" means of reducing turnover.

qualification (among others). To assess the importance of the relationship for these firms, I evaluated the probability of CVT provision at different turnover rates. The conditional-effect plot in Figure 1 depicts the results (including 95\% confidence intervals).

The chart shows that at turnover rates beyond $10 \%$ the probability of CVT provision is significantly lower in firms with low skill needs (i.e. employing workers without formal vocational qualification) than in firms with high skill. The average marginal effect (AME) of turnover is -0.004 for firms with low skill needs, stating that an increase in turnover of 1 percentage point goes along with an average reduction in the probability of CVT provision of roughly 0.4 percentage points. Given the average scope of turnover ( 9.0 percent in the full sample), realistic changes in turnover rates would thus affect CVT incidence only slightlys.

Now, does this finding point at poaching being a relevant threat to firms with low skill needs? Or does it point at reversed causality, i.e. CVT being able to reduce turnover especially in the respective firms?

On the one hand, one might argue that poaching should be much more of an issue in firms with higher skill needs (and higher levels of CVT provision) as highly qualified employees can be expected to aspire toward optimization of wages and career opportunities, whereas workers with no formal qualification can be expected to seek employment security in the first instance. Thus, if we could interpret the relationship between turnover and CVT incidence as reflecting the causal influence of turnover on training provision, then why would this effect pertain only to firms with presumably lower qualification requirements? Considering this question, one might tend to think that a negative relationship between turnover and CVT provision rather reflects an HR policy aiming at employee retention. CVT provision may be nothing but one component of such a policy. This interpretation can be backed up with information on the reasons for employers' CVT commitment, or CVT abstinence, respectively. For instance, among other potential reasons for not having provided CVT in 2010 interviewees from abstinent firms assigned by far the lowest priority to the risk of labor turnover. Conversely, three out of four representatives of firms which did provide CVT in 2010 said that tying employees to the company was one reason - among others - for their CVT spending ${ }^{\mathrm{t}}$. 


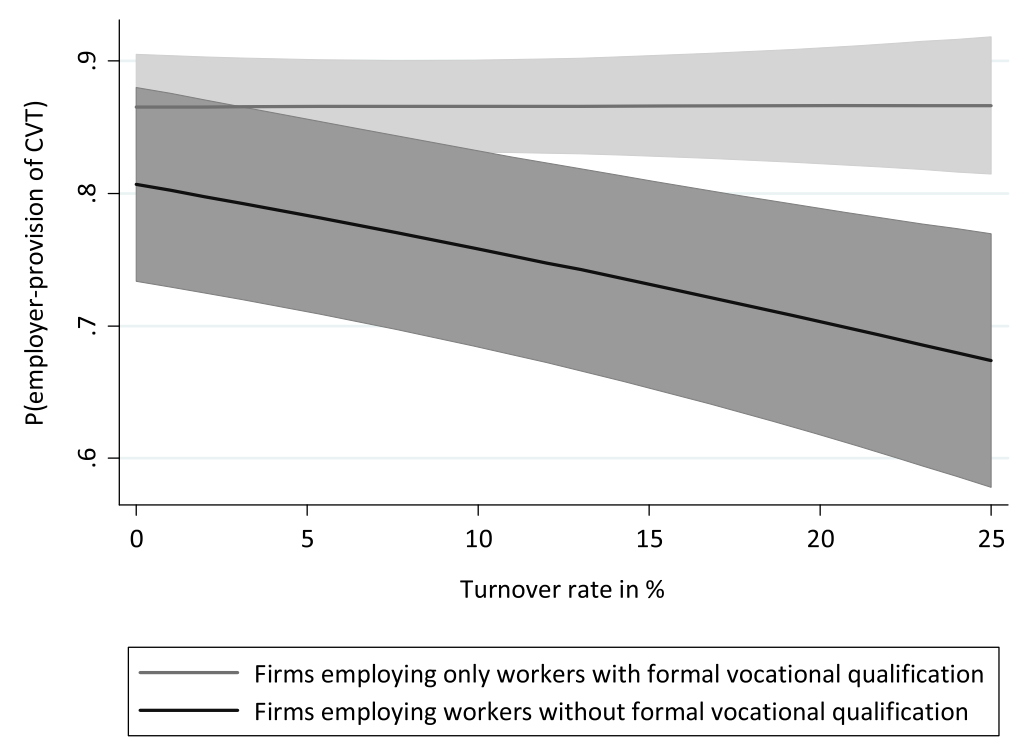

Figure 1 Turnover and predicted probabilities of CVT incidence for firms with high and low skill needs. Notes: Shaded areas illustrate $95 \%$ confidence intervals.

On the other hand, one might argue that no relationship rather than a negative relationship should be observed, if training was actually used to reduce turnover rather than reduced by turnover. This is, because rising turnover rates would then cause firms to provide CVT to bring back down turnover rates, making it difficult to observe any clear relationship in a cross-sectional data. Also, one could reason that, indeed, poaching may be of greater influence for firms with low skill needs, because it is feasible to do without CVT in such firms, whereas CVT may be indispensable when skill needs are high. In other words: when CVT is less crucial to firm productivity, employers might react more sensitively to changes in turnover. Thus, even though descriptive figures on employers' (non-)training motives do not point at turnover being perceived as a constraint to CVT in the majority of firms, some firms with relatively low skill needs may actually abandon CVT because of staff fluctuation.

Support for this argument emanates from a further modification of the estimation model. When including a variable indicating whether firm representatives regard CVT as a "very important" means of reducing turnover and interacting this variable with turnover, the negative coefficient of turnover is reinforced (Table 1, column 6). The latter now reflects the relationship between turnover and CVT incidence for firms not regarding CVT as a "very important" means of reducing turnover. The interaction term is positive, but not significant, indicating no clear relationship between turnover and training incidence for the remaining firms. As discussed in the previous paragraph, this is a plausible finding for firms attempting to reduce turnover with the help of CVT. Both results the reinforced coefficient of turnover and the non-significant interaction term carrying the opposite sign can carefully be interpreted as evidence in favor of a causal interpretation. Note, however, that the share of firms not regarding CVT as a means of reducing turnover is rather low. Regardless of whether firms provided CVT or not, $86 \%$ of the interviewed firm representatives look at CVT as a "rather important" or "very important" means of tying employees to the company. Among different other 
factors only one - the working atmosphere - is viewed by the interviewees to be even more relevant than CVT to reduce turnover. Thus, a potential poaching problem appear to affect only few firms, even if a causal interpretation of the estimated relationship for firms with low skill needs is possible $\mathrm{u}^{\mathrm{u}}$.

A further remarkable finding is that training incidence appears to be considerably lower among firms whose representatives explicitly stated that potential benefits to outside firms played a role in their training decision. This finding is robust across all estimated specifications. Hence, regardless of the actual dimension of turnover, some firms appear to abstain from CVT provision because they are aware of a potential free-rider problem. Note, however, that the average marginal effect is lower than suggested by the odds ratio from the regression output: ceteris paribus the probability of CVT provision is about 8 percentage points lower in the group of firms whose representatives stated to consider externalities when taking decisions on CVT provision. Given that only about $16 \%$ of firm representatives said so in the survey, it is obvious that the share of firms potentially withdrawing from CVT provision because of a free-rider problem is rather small ${ }^{\mathrm{V}}$.

\section{Turnover and CVT spending}

Table 2 displays the results from estimating employer-spending on CVT via OLS (see Equation 2). Other than the Logit estimates presented before, these estimates consider only firms actually having provided CVT in 2010. They also take account of whether the provided training was predominantly transferable or specific. Apart from that, model specifications are the same as in the binary case. Table 2 is constructed in the same manner as Table 1. It shows that the coefficient of turnover carries a negative sign across almost all specifications; but there is no significant relationship between turnover and spending on $\mathrm{CVT}^{\mathrm{w}}$. Also, firms providing predominantly specific training do not spend significantly higher amounts than firms providing predominantly transferable training.

As in the binary model, I included in the regression model interaction terms. However, nothing hints at differences in the relationship between turnover and CVT spending between the examined groups of training firms ${ }^{\mathrm{x}}$. Especially, to test proposition 2, a multiplicative term between the degree of training specificity and turnover was considered, such that the coefficient relating to turnover rate 1 reflects the relationship between turnover and CVT spending for firms providing predominantly transferable training. Estimating the specification, the coefficient of the multiplicative term carries the expected positive sign indicating that poaching could be less important in connection with specific training than in connection with transferable training. It is, however, non-significant, making it impossible to build a case on it (Table 2, column 5).

Eventually, even training firms whose representatives stated to be sensitive of the benefits to outside firms do not spend significantly lower amounts on CVT than other training firms.

How can these findings be explained? One potential explanation is that it may be possible in practice to mitigate the problem of 'non-excludability' associated with training investment. For instance, using payback clauses firms are able to minimize the risk of turnover, render skills 'excludable', and make them de facto a private good - at least for a given period of time. At the downside, there may be some uncertainty as to whether such agreements between the firm and the worker are actually legally valid. For Germany such a problem has been reported by Alewell (1998). Basically, valid payback 
Table 2 OLS estimation of CTV spending

\begin{tabular}{|c|c|c|c|c|c|c|}
\hline Dep. variable: $\log (C V T$ exp. $(€) /$ worker) & $(1)$ & (2) & (3) & $(4)$ & $(5)$ & (6) \\
\hline Turnover 1 & -0.004 & -0.003 & -0.004 & -0.001 & -0.001 & 0.003 \\
\hline$(\ln \%)$ & $(0.005)$ & $(0.005)$ & $(0.005)$ & $(0.005)$ & $(0.005)$ & $(0.006)$ \\
\hline Turnover 2 & -0.007 & -0.003 & -0.003 & -0.0003 & -0.0003 & -0.0003 \\
\hline$(\ln \%)$ & $(0.020)$ & $(0.014)$ & $(0.015)$ & $(0.014)$ & $(0.014)$ & $(0.014)$ \\
\hline Specifity of CVT & -0.008 & -0.035 & -0.057 & -0.087 & -0.118 & -0.090 \\
\hline$(0=$ rather general, 1 = rather specific $)$ & (0.166) & (0.154) & (0.146) & $(0.134)$ & $(0.162)$ & $(0.134)$ \\
\hline TO1 X CVT specificity & & & & & 0.005 & \\
\hline (Interaction term) & & & & & $(0.015)$ & \\
\hline Collective labor agreement & & & $-0.270^{*}$ & $-0.335^{* *}$ & $-0.332^{* *}$ & $-0.337^{* *}$ \\
\hline ( $0=$ no, $1=$ yes $)$ & & & $(0.142)$ & $(0.133)$ & $(0.132)$ & $(0.132)$ \\
\hline Worker representation & & & 0.251 & 0.109 & 0.106 & 0.109 \\
\hline$(0=$ no, $1=$ yes $)$ & & & $(0.155)$ & $(0.164)$ & $(0.163)$ & $(0.163)$ \\
\hline Innovativeness & & & $0.324^{* * *}$ & $0.266^{* *}$ & $0.268^{* *}$ & $0.267^{* *}$ \\
\hline$(0=$ low, $1=$ high $)$ & & & $(0.120)$ & $(0.115)$ & $(0.115)$ & $(0.115)$ \\
\hline $\mathrm{R}+\mathrm{D}$ activities & & & 0.074 & 0.045 & 0.044 & 0.039 \\
\hline$(0=$ no, $1=$ yes $)$ & & & $(0.139)$ & (0.138) & $(0.139)$ & $(0.140)$ \\
\hline Demands on workers & & & -0.136 & -0.066 & -0.065 & -0.073 \\
\hline$(-1=$ increasing, $0=$ stable, $1=$ decreasing $)$ & & & (0.158) & $(0.153)$ & $(0.154)$ & $(0.153)$ \\
\hline Qualification structure & & & -0.142 & -0.098 & -0.102 & -0.100 \\
\hline$(1$ = employment of workers w/o degree, 0$)$ & & & $(0.138)$ & $(0.126)$ & $(0.124)$ & $(0.125)$ \\
\hline Wages & & & & $0.511^{* * *}$ & $0.510^{* * *}$ & $0.505^{* * *}$ \\
\hline (logged) & & & & $(0.148)$ & $(0.148)$ & $(0.148)$ \\
\hline CVT professionalism & & & & $0.364^{* * *}$ & $0.365^{* * *}$ & $0.369^{* * *}$ \\
\hline$(0=$ low, $1=$ high $)$ & & & & $(0.111)$ & $(0.111)$ & $(0.112)$ \\
\hline Training funds receipts & & & & 0.298 & 0.292 & 0.304 \\
\hline$(0=$ no, $1=$ yes $)$ & & & & $(0.205)$ & $(0.207)$ & $(0.206)$ \\
\hline Payback clauses & & & & $0.448^{* * *}$ & $0.448^{* * *}$ & $0.518^{* * *}$ \\
\hline$(0=$ no, $1=$ yes $)$ & & & & $(0.123)$ & $(0.123)$ & $(0.144)$ \\
\hline TO1 X payback clauses & & & & & & -0.011 \\
\hline (Interaction term) & & & & & & $(0.011)$ \\
\hline CVT agreements & & & & 0.095 & 0.097 & 0.0946 \\
\hline ( $0=$ no, $1=$ yes $)$ & & & & $(1.177)$ & $(1.177)$ & $(0.176)$ \\
\hline Recognition of externalities & & & & 0.165 & 0.165 & 0.162 \\
\hline (Self-reported; $0=$ no, $1=$ yes) & & & & $(0.174)$ & $(0.174)$ & $(0.146)$ \\
\hline Sensitivity to risk of turnover & & & & 0.006 & 0.010 & 0.009 \\
\hline (Self-reported; $0=$ no, $1=$ yes) & & & & $(0.147)$ & $(0.148)$ & $(0.146)$ \\
\hline Industrial agglomeration & & -0.071 & -0.064 & 0.003 & 0.002 & 0.001 \\
\hline$(0=$ no, $1=$ yes $)$ & & $(0.126)$ & $(0.129)$ & $(0.129)$ & $(0.129)$ & $(0.129)$ \\
\hline Metropolitan distance & & -0.116 & 0.114 & -0.125 & -0.124 & -0.122 \\
\hline$(0=$ up to $50 \mathrm{~km}, 1=$ more than $50 \mathrm{~km})$ & & $(0.132)$ & (0.133) & $(0.129)$ & $(0.131)$ & $(0.131)$ \\
\hline \multicolumn{7}{|l|}{ Firm size (ref. 5-9 Besch.) } \\
\hline \multirow[t]{2}{*}{ 10-49 employees } & & $-0.318^{* *}$ & $-0.371^{* * *}$ & $-0.442^{* * *}$ & $-0.440^{* * *}$ & $-0.440^{* * *}$ \\
\hline & & $(0.134)$ & $(0.135)$ & $(0.132)$ & $(0.133)$ & $(0.132)$ \\
\hline \multirow[t]{2}{*}{ 50-249 employees } & & $-0.643^{* * *}$ & $-0.714^{* * *}$ & $-1.014^{* * *}$ & $-1.009^{* * *}$ & $-1.002^{* * *}$ \\
\hline & & $(0.145)$ & $(0.170)$ & $(0.176)$ & $(0.175)$ & $(0.176)$ \\
\hline
\end{tabular}


Table 2 OLS estimation of CTV spending (Continued)

\begin{tabular}{lllllll}
\hline 250 or more employees & & $-0.539^{* * *}$ & $-0.675^{* * *}$ & $-1.081^{* * *}$ & $-1.081^{* * *}$ & $-1.078^{* * *}$ \\
& & $(0.159)$ & $(0.209)$ & $(0.219)$ & $(0.219)$ & $(0.218)$ \\
\hline Industry controls & NO & YES & YES & YES & YES & YES \\
Region controls & NO & YES & YES & YES & YES & YES \\
\hline Constant & $5.354^{* * *}$ & $5.669^{* * *}$ & $5.810^{* * *}$ & 0.593 & 0.612 & 0.588 \\
& $(0.085)$ & $(0.787)$ & $(0.794)$ & $(1.633)$ & $(1.626)$ & $(1.629)$ \\
\hline $\mathrm{N}$ & 974 & 974 & 972 & 962 & 962 & 962 \\
Pseudo- $R^{2}$ & 0.004 & 0.166 & 0.201 & 0.289 & 0.290 & 0.291 \\
\hline
\end{tabular}

Notes: *** $p<0.01,{ }^{* *} p<0.05,{ }^{*} p<0.1$. Multiply imputed data. Reported $R^{2}$ relates to the respective estimates based on a single imputation approach. Column 5 considers an interaction term between turnover rate 1 and training specificity. Column 6 considers an interaction term between turnover rate 1 and the existence of payback clauses.

clauses must not discriminate employees unduly. Legal practice has established a number of criteria for appropriate agreements (Lakies 2012). Yet, some employers may find it risky to close such a contract and decide to abstain from utilizing this instrument. Another drawback of payback clauses could be given by the potential demotivation of workers who might perceive such clauses as a signal of distrust, or as discriminating. Nevertheless, such contracting is applied in quite many firms in Germany (see Mueller 2012) . $^{\mathrm{y}}$.

When including a multiplicative term interacting the existence of payback clauses with turnover, no significant difference emerges in the relationship of turnover and CVT spending between firms applying payback clauses and firms not applying payback clauses (Table 2, column 6). This finding, however, is not surprising as the application of payback clauses in a firm could mitigate a poaching problem just as well as indicate it. More importantly, it appears from Table 2 that establishments spent considerably higher amounts on CVT when applying at least one payback clause. Regardless of what is cause and effect, this finding suggests that payback clauses serve the purpose of safeguarding training returns to firms quite well ${ }^{\mathrm{z}}$.

\section{Conclusions}

This paper has presented analyses of the relationship between turnover and firms' dedication to CVT. The work has exploited novel survey data on firms in Germany (BIBB-FluCT data) providing details on labor turnover as well as employers' CVT activities.

Regression analyses of these data point at a negative correlation between turnover and CVT incidence for firms with low skill needs (i.e. firms employing workers without a formal vocational qualification). Even though the direction of the effect remains debatable, further analysis gives reason to think that the relationship could actually reflect the causal influence of turnover on training provision. More precisely, if the relationship reflected the inverse effect, the latter should be observed especially in firms explicitly looking at CVT as a "very important" means of reducing turnover. However, no clear negative relationship between turnover and CVT incidence appears in these firms.

Further on, the computed effect is small in scope. For firms with low skill needs it indicates an average increase in the probability of CVT provision of roughly 0.4 percentage points when turnover rates drop by one percentage point. Thus, only a minority of 
firms seems to actually forego CVT because of high turnover. In line with this, fewer than $7 \%$ of non-CVT firms' representatives said that turnover was a reason for their firms' CVT abstinence. This makes turnover the least important out of eight potential reasons given in the survey questionnaire.

Further on, the scope of training spending in firms providing CVT does not appear to be related to turnover at all. Instead, the analyses indicate that payback clauses go along with much higher employer spending on CVT. Such agreements may help employers mitigate the problem of 'non-excludability', turn skills into part-time private goods and appropriate training returns.

In summary, the presented findings seem hardly sufficient to fundamentally substantiate the poaching hypothesis for the case of CVT in general. It would thus not be safe to argue - based on the results - that most firms in Germany under-invest in CVT ${ }^{\mathrm{aa}}$. However, not all facets of poaching may be observable when looking at turnover rates. For instance, the regression results show that firms paying attention to potential benefits of their training activities to outside firms (externalities) are less likely to provide CVT. They might fear a free-rider problem regardless of the actual dimension of turnover. Notwithstanding, even this effect is limited in scope suggesting that only few firms actually withdraw from CVT because of a perceived free-rider problem.

Overall, the analyses seem to suggest that the important works of Acemoglu (1997), Acemoglu and Pischke (1999a, b) and Stevens (1994, 1996), which do not distinguish between initial and continuing training, may be less relevant for training going beyond initial on-the-job educational programs. Intuitively, this would not be too surprising as many of such training activities are probably small in scope and their cost are too low (compared with total payroll size) for the training decision to depend on the threat of poaching. Hence, one could argue that initial training or tertiary training (in which firms in Germany do still not participate greatly) is much more prone to an underinvestment problem due to poaching (e. g. Muehlemann and Wolter 2011). On the other hand, the results point at the possibility of property rights definition for skills developed during employer-provided training. In many cases, payback clauses may help employers eliminate the cause of the poaching problem.

An obvious limitation of the presented study is that the financial contribution of workers has been disregarded in the analyses. Thus, the results depend on the presumption that market conditions have been controlled for effectively such that turnover rates do not capture market characteristics. However, this restriction would create a much more serious issue, if the analyses had delivered strong evidence for a generally negative relationship between turnover and employer-provided CVT. Nevertheless, further studies (e.g. in other countries) could serve to ensure external validity. Ideally, future studies should also integrate information on both the financial efforts of employers as well as employees.

\section{Endnotes}

${ }^{a}$ Note that there is a strand of literature focusing on the effect of training on coworker productivity (e.g. De Grip and Sauermann 2012). Such productivity spillovers are frequently termed externalities in these works. This terminology, unfortunately, is misleading as externalities are by definition non-internalized benefits. Productivity spillovers due to training, however, may well be reflected in the wage structure. It is hardly 
possible to judge empirically whether they are indeed, or not. Wage differences embed many more aspects than just differences in productivity and the compensation for knowledge and productivity spillovers. In summary, productivity spillovers and poaching externalities are two different concepts that should not be put on the same level.

${ }^{\mathrm{b}}$ The theoretical thoughts on poaching externalities of employer-provided training have been developed in the context of Anglo-Saxon educational systems. That is why the authors of the aforementioned theoretical works do not distinguish between initial and continuing vocational training. Translating the concept of poaching with respect to the German educational system it is typically thought to apply to initial training activities, which consist of two- or three-year educational programs leading to recognized educational degrees. An example is given by the apprenticeship in the dual system, which combines on-the-job-training and formal schooling. The study at hand, however, investigates whether the under-investment hypothesis holds for continuing vocational training (CVT) activities. The latter are on average much smaller in scope and also of more specific content than initial training activities as in Germany CVT typically occurs after completion of initial education. Nevertheless, it makes sense to look at continuing training as the poaching argument is used in the debate on the financing of continuing training, too (Bosch 2012, p10-11).

${ }^{c}$ To ensure that a relationship between two variables is not due to reversed causality it is necessary to extract the truly exogenous fraction of the explanatory variable. A method to achieve that is given by the approach of instrumental variable (IV) estimation. For this approach to be applicable, however, it is necessary to find a variable that is correlated sufficiently strong with the suspect variable (here: turnover), but that does not influence the dependent variable (here: employer-provided training investment) directly and, vice versa, is not affected by the latter either (exogeneity assumption). Such a variable can serve as an instrument and help safeguard against reversed causality issues. In Mueller (2013a), an attempt has been made to instrument turnover rates with geographical information. There are, however, objections against the validity and the relevance of the instrumental variable. For this reason, the respective analyses are not part of the present study.

${ }^{\mathrm{d}}$ As Brunello and De Paola (2009) focus on the group of individuals aged 25 to 54, most initial vocational training (like apprenticeships in dual vocational education systems) is likely to be precluded from their analysis.

${ }^{\mathrm{e}}$ This measure of turnover risk may capture a positive effect on training stemming from expanding companies that permanently increase their staff and at the same time provide training.

${ }^{\mathrm{f}}$ Gerlach and Jirjahn (2001) provide another study on the determinants of employerprovided CVT in German firms. Using data from manufacturing establishments in the state of Lower Saxony, they consider a variety of aspects inspiring greatly the choice of covariates applied to the model analyzed in this paper. Turnover, however, is not a subject of their analyses.

${ }^{g}$ Firms' training exposure and labor turnover in German firms are available from the European Continuing Vocational Training Survey (CVTS) and the IAB Establishment Panel. However, no dataset combining both aspects in the way necessary for the intended analyses has existed so far.

${ }^{\mathrm{h}}$ The survey was conducted by aproxima Gesellschaft für Markt und Sozialforschung $\mathrm{mbH}$ seated in Weimar, Germany. Further information on the survey is included in the 
field report. The field report and the questionnaire are published on the BIBB website (URL: http://www.bibb.de/de/wlk54493.htm).

${ }^{\mathrm{i}}$ Of course, the probability of training provision is strongly related to firm size. Among the sampled units, firms with 250 or more employees have the highest training incidence (92.8\%, not weighted), firms with fewer than 10 employees the lowest (67.2\%, not weighted).

jOn a univariate descriptive level, there is no clear relationship with firm size (firms with 5-9 employees spent 325 Euros, firms with 10-49 employees 231 Euros, firms with 50 to 249 employees 199 Euros, and firms with firms with at least 250 employees 284 Euro).

${ }^{k}$ Elsewhere, emphasis is put on a Tobit regression model (see Mueller 2013a; Mueller 2013c) employing CVT spending per worker (not logged) as the dependent variable and relying on a slightly different specification of the right-hand side of the model. The Tobit model permits estimation of dependent variables with corner-solution outcomes (see Wooldridge 2009, Ch. 17.2) such as the outcome "zero spending on CVT" in the given application. It can be interpreted to combine the two separate models presented in this paper. Separate estimation, however, illustrates much better the differences between the training decision and the scope of employer-provided training.

${ }^{\mathrm{l}}$ For further details on the construction of all covariates, see the appendix of this article.

${ }^{\mathrm{m}}$ Further summary statistics on CVT investment and turnover rates are given in Mueller (2012).

${ }^{\mathrm{n}}$ As an alternative to the distance measure, I deployed (logged) population figures pertaining to the largest city within a 45 minutes travel distance. Both variables provide a measure of how many potentially competing employers exist in the local labor market. They are highly, but not perfectly correlated. Both alternatives deliver highly compatible results.

${ }^{\circ}$ Both variables are correlated, but not high enough to cause a multicollinearity issue when including them both in a regression. The correlation coefficient is roughly 0.25 . Also, the existence of payback clauses is correlated with both the sensitivity to turnover $(-0.03)$ and the recognition of externalities $(0.12)$, but not at all high enough to pose a problem for the analyses.

${ }^{\mathrm{P}}$ Even after imputation, the number of observations available for regression analyses is lower by more than 100 cases when wages are included in the imputations and regression models.

${ }^{\mathrm{q}}$ Regression analyses based on the non-imputed data deliver only marginally different results, which is why I consider details on the imputation procedure and the imputation model to be of little interest to the reader. Given the scope of a thorough description, I decided to not overload this paper with the respective details. The latter, however, are available from the author upon request. Also, an imputation model only slightly different from the one applied in this paper can be looked up in Mueller (2013a). Note that Stata does not compute goodness-of-fit measures after estimation based on multiply imputed data, which is why I use $R^{2}$ (OLS) and Pseudo- $R^{2}$ (Logit) from estimates based on single imputed data.

${ }^{\mathrm{r}} \mathrm{I}$ do not discuss the coefficients of every covariate in the regression. Most of the coefficients are in line with expectations and with what is known from other empirical 
studies. A noteworthy result is that greater distance from metropolitan areas is correlated with significantly lower training incidence in two specifications - independent of turnover. The relationship vanishes when (highly endogenous) HR policy variables are included in the model. Thus, training incidence in far-off regions with lower turnover may not necessarily be higher; it may actually suffer from potentially none-up-to-date HR policies.

${ }^{s}$ The marginal effect computation and the conditional effect plots are based on a single-imputation approach as the estimation sample varies across imputations in the multiple imputation approach making it difficult to compute the AME. As stated before, results depend only marginally on the number of imputations. Also, because of the varying estimation samples it is difficult to present nested models with equal number of observations for each estimated specification when exploiting multiply imputed data. As a test, I ran the regressions based on single-imputed data using for all model specifications only those observations for which estimation of the full specification (cf. column 4 of Tables 1 and 2) is possible; the results are substantially stable. The same applies to the OLS estimate presented in "The same applies to the OLS estimates".

${ }^{\mathrm{t}}$ More details on firm representatives' perceptions of training reasons and reasons for training abstinence can be found in Mueller (2012).

${ }^{\text {u}}$ Note that two different questions were asked at different stages of the interview. In the beginning of the interview, all firm representatives were asked to state how important they found CVT in terms of reducing turnover. $86 \%$ of the firm representatives said that it was "rather important" or "very important". Then, towards the end of the interview, representatives who had stated that their firm had financed CVT in 2010 were asked whether the reduction of turnover had actually been a reason for their own firms' spending. Roughly 57\% said that this had been the case; three out of four representatives even said that it had been a very important reason. For the purpose of using it in a regression on CVT incidence, only the first measure is applicable. Both measures, however, are highly collinear. I also ran a robustness test with a recoded moderator variable indicating whether firm representatives regard CVT as a "rather important" or "very important" means of reducing turnover. The interpretations given in the text are strengthened based on this test.

${ }^{v}$ For the sake of completeness, note that no interaction effect surfaces when multiplicative terms between turnover and firms size are included in the regression models (not displayed in Table 2).

${ }^{\text {w}}$ Surprisingly, the presence of collective labor agreements appears to be negatively related to firms' training spending. This effect seems to contradict intuition and needs further investigation. A case should not yet be built on this result.

${ }^{\mathrm{x}}$ Table 2 merely shows the specifications including interaction terms of turnover with the variables indicating the degree of training specificity and the existence of payback clauses. I do not report the regression results coming along with the inclusion of other multiplicative terms as these results do not contribute any further information to the understanding of the relationship between turnover and training spending.

${ }^{y}$ In-depth analyses of the determinants of payback contracting are currently being conducted in a further research project and will be reported in a different paper.

${ }^{\mathrm{z}}$ Also, wages may help retain employees. Obviously, firms offering higher wages spend higher amounts on CVT, too. Either, wages and CVT are used simultaneously as 
components of an HR policy targeted at attracting high-quality employees and tying them to the company, or wages are higher because trained employees require some of the monetary returns they could earn in the market.

${ }^{\text {aa }}$ Mueller $(2013 \mathrm{a}, \mathrm{c})$ relies on a different specification of the imputation and regression models (most importantly, wages are excluded; industries and regions are collapsed to few categories). Moreover, the focus is on Tobit estimation for the full sample with training spending as the dependent variable (instead of the OLS estimation of logged training spending for the training firms subsample). The analyses lead to slightly different results and interpretations. Most importantly: with regard to the effect of turnover on training incidence, the estimates do not deliver a significant interaction effect implying a negative relationship for firms employing non-qualified workers. Also, in Mueller (2013a, c) instrumental variable estimates are reported showing no causal relationship between turnover and training. IV estimates have been disregarded in the present paper because their explanatory power would be low given the different estimation strategy, model specifications, and results. All in all, the conclusions drawn from the analyses in Mueller (2013a, c) are somewhat more skeptical in terms of whether there is a causal effect of turnover on training. Nevertheless, the evidence furnished in the present paper must be put into perspective, too, as the scope of a potential poaching problem and the share of firms suffering from it may be small. So, the bottom line is essentially the same as in Mueller (2013a, c): based on the analyses it is not possible to make a strong case in favor of a general poaching problem relevant to the majority of firms.

\section{Appendix - Construction of covariates}

Turnover rate 1 [in \%] - Number of employees who left a specific firm during the year 2010, divided by the total number of employees at a given due date (June $30^{\text {th }} 2010$ ), as far as the leaving persons could in principle be employed by other firms after separation. This applies to persons who were dismissed by the firm, persons who quitted their jobs, persons with expiring temporary work contracts, and persons whose positions were discarded for the reasons of restructuring or rationalization. This measure of turnover, however, does not account for relocation, parental leave or similar reasons for employees leaving the firm and perpetuating a work relationship with the employer. Also, cases of retirement and occupational disability are not reflected by this rate. For the purpose of a more intuitive interpretation of regression coefficients, the rate was multiplied by 100 . Alternatively, all estimates were repeated in ignorance of any dismissals caused by restructuring or rationalization activities. These estimates, however, are not reported as the results do not differ notably from the ones presented in this paper.

Turnover rate 2 [in \%] - Number of employees who left a specific firm during the year 2010 divided by the total number of employees at a given due date (June $30^{\text {th }}$ 2010), as far as the leaving persons could not be employed by other firms after separation. This includes cases of relocation, retirement or occupational disability. Instances of parental leave are ignored because a work relationship still exists in these cases. For the purpose of a more intuitive interpretation of regression coefficients, the rate was multiplied by 100 .

Specificity of CVT [0/1] - Indicator specifying whether skills developed during employer-provided CVT in 2010 were predominantly specific to the observed firm 
$(=1)$, or predominantly applicable in other firms, too $(=0)$. When answering the respective question in the interview, firm representatives had to decide for one of both response options.

Collective labor agreement [0/1] - Indicator specifying for each firm whether at the time of the interview a collective labor agreement was applied in the firm $(=1)$, or $\operatorname{not}(=0)$.

Worker representation [0/1] - Indicator specifying for each firm whether an institutionalized worker representation on a legal basis (e. g. in the form of work councils, staff councils etc.) existed at the time of the interview $(=1)$, or not $(=0)$.

Innovativeness [0/1] - Indicator specifying firms' innovativeness. This dichotomous variable exploits information on three items: the development or introduction of product improvements, the development or introduction of process improvements and the development or introduction of product innovations during the year 2010. Improvements of products or processes each were assigned a score of 1 point. Product innovations were assigned 2 points, if at the time of introduction no other competing product existed, and they were assigned 1 point, if a competing product was already available for customers. When firm representatives could not give information regarding one or more of the three items, zero points were assigned. To construct the indicator variable, innovativeness of firms was graded as "low" when the total score of a firm was 0-1 points $(=0)$, and it was graded as "high" when the total score was $2-4$ points $(=1)$.

$R+D$ activities [0/1] - Indicator specifying for each firm whether $\mathrm{R}+\mathrm{D}$ activities take place in the firm on a regular basis. $\mathrm{R}+\mathrm{D}$ activities in other business units or at other locations are not considered.

Demands on employees [-1/0/1] - Indicator specifying whether the demands on firms' employees had increased $(=-1)$, decreased $(=1)$, or remained rather stable $(=0)$ during the three years preceding the interview.

Qualification structure [0/1] - Indicator specifying whether a specific firm employed workers without a formally recognized vocational qualification at the due date $(=1$, applies to roughly $40 \%$ of the firms in the sample), or not $(=0)$.

Wages [in Euros (logged)] - This variable is computed by dividing total payroll size by the total number of employees at the given due date (June $30^{\text {th }} 2010$ ). The variable is logged to let the estimate of a potential effect on training depend on the level of wages. Note that average annually working hours per employee are unknown. Hence, payroll size must be related to the number of employees, giving the annual gross wage per employee. In this approach, part-time work is neglected. Consequently, at a given hourly wage level the estimate of annual gross wages will be lower the higher the share of part-time workers in a firm. Thus, wage levels (besides other covariates, such as the industry controls) will at least partially capture the extent of part-time work in a firm, which may lead to lower estimates of the relationship between wages and training.

CVT professionalism [0/1] - Indicator specifying the degree of professionalism in firms' CVT management. This variable exploits information on six items. These items track whether firms

- perform analyses to identify qualification needs,

- compile written CVT plans or programs,

- conduct interviews with employees to identify qualification needs, 
- validate the success of CVT in written or practical exams,

- validate the success of CVT based on observations of trainees in their work environment, or

- validate the success of CVT by monitoring the results of trainees work.

A score of 1 point was awarded for each implemented item. If no information was available regarding one or more items, each of the latter was awarded zero points. To construct the indicator variable, CVT professionalism of firms was graded as "low" if the total score was $0-3$ points $(=0)$, and it was graded as "high" if the total score was 4-6 points $(=1)$.

Training funds receipts [0/1] - Indicator specifying for each firm whether it had received grants from levy-based training funds in $2010(=1)$, or not $(=0)$.

Payback clauses [0/1] - Indicator specifying for each firm whether payback clauses had been in effect at the time of the interview to provide for employees leaving the firm after CVT $(=1)$, or not $(=0)$.

$C V T$ agreements [0/1] - Indicator specifying for each firm whether formal agreements concerned with CVT existed $(=1)$, or not $(=0)$, between the firm and worker representation on the firm-level (e.g. work councils) at the time of the interview. Such agreements might regulate anything from a general mission statement regarding CVT for employees to very specific guidelines as to how much CVT the firm should provide for each worker and who should pay for it.

Recognition of externalities [0/1] - Firm representatives were asked whether the possibility of outside firms benefitting from their firms' CVT investment plays a role in their CVT planning or CVT decisions. The dichotomous variable indicates whether interviewees said "yes" $(=1)$, or "no" $(=0)$.

Sensitivity to risk of turnover [0/1] - Firm representatives were asked whether the risk of employees leaving the firm after CVT plays a role in their training planning or training decisions. The dichotomous variable indicates whether interviewees said "yes" $(=1)$, or "no" $(=0)$.

Industrial agglomeration [0/1] - Indicator specifying whether firms belong to a regional industrial agglomeration $(=1)$, or not $(=0)$. An industrial agglomeration is assumed to exist when the interviewees stated that there were clearly more firms belonging to the same industry in their region than in other regions.

Metropolitan distance [0/1] - Indicator specifying for each firm whether it is located more than 50 kilometers $(=1)$, or 50 kilometers at the most $(=0)$, from the nearest of 14 German cities with more than 500,000 inhabitant. The measure of distance refers to the car driving distance.

Firm size $[0 / 1,4 \mathrm{x}]$ - Four dichotomous variables specifying to which of four categories a firm belongs with respect to firm size. The categories are: firms with 5 to 9 employees, firms with 10 to 49 employees, firms with 50 to 249 employees, firms with 250 or more employees. In the analyses, the first group (5 to 9 employees) serves as the reference category. Employees are considered to be persons having a work contract with the firm or a parent company. This definition excludes leased workers, freelancers, trainees who do not have a work contract with the firm (außerbetrieblich Auszubildende) and interns.

Region controls [16 dichotomous variables] - Indicator specifying for each firm whether it is located in East Germany $(=1)$, or West Germany $(=0)$. For each of 16 
regions (Bundesländer), the variables indicate whether a firm belongs to a specific region $(=1)$, or not $(=0)$.

Industry controls [21 dichotomous variables] - Information on industry affiliation is principally based on the upper level of the German classification system WZ08. For each of 21 industries, the variables indicate whether a firm belongs to a specific industry $(=1)$, or not $(=0)$.

Competing interests

The author declares that he has no competing interests.

\section{Acknowledgement}

This study was funded by the Federal Institute of Vocational Education and Training (BIBB), Germany. The author is fully responsible for the survey design, data analyses and interpretation of the results. The survey interviews were carried out by aproxima Gesellschaft für Markt und Sozialforschung mbH seated in Weimar, Germany. Both the full research report and the field report by aproxima $\mathrm{GmbH}$ are available via the BIBB website (see http://www.bibb.de/de/ wlk54493.htm).

I wish to thank Guenter Walden, Friederike Behringer, Klaus Berger, Dick Moraal, the participants of the Arbeitskreis quantitative Methoden (July 2012) and the Projektkolloquium (April 18, 2013) at the BIBB, the members of the BIBB scientific advisory council, as well as the participants of the 3rd Congress on Research in Vocational Education and Training held in Berne/Zollikofen (March 13-14 2013) for helpful comments. Also, I am quite indebted to two anonymous referees, who provided valuable suggestions having improved the paper greatly.

Received: 27 June 2013 Accepted: 17 December 2013

Published: 28 January 2014

\section{References}

Acemoglu D (1997) Training and Innovation in an Imperfect Labour Market. Rev Econ Stud 64(3):445-464, doi: 10.2307/ 2971723

Acemoglu D, Pischke J-S (1999a) Beyond Becker: training in imperfect labor markets. Econ J 109:F112-F142

Acemoglu D, Pischke J-S (1999b) The structure of wages and investment in general training. J Polit Econ 107(3):539-573

Alewell D (1998) Warum finanzieren Arbeitgeber transferierbare Weiterbildung? Schmalenbachs Zeitschrift für betriebswissenschaftliche Forschung 50:315-335

Becker GS (1962) Investment in human capital: a theoretical analysis. J Polit Econ 70(5):9-49

Bosch G (2012) Weiterbildungsfonds - ein Finanzierungsmodell auch für Deutschland? Berufsbildung in Wissenschaft und Praxis 41(1):23-26

Brunello G, De Paola M (2008) Training and economic density: some evidence from Italian provinces. Labour Econ 15:118-140

Brunello G, De Paola M (2009) Is there under-provision of training? Empirical Research in Vocational Education and Training 1(1):1-18

Brunello G, Gambarotto F (2004) Agglomeration Effects on Employer-Provided Training: Evidence from the UK. IZA Discussion Paper 1055, Bonn

De Grip A, Sauermann J (2012) The effects of training on own and co-worker productivity: evidence from a field experiment. Econ J 122(560):376-399, doi: 10.1111/j.1468-0297.2012.02500.x

Feuer MJ, Glick HA, Desai A (1987) Is firm-sponsored education viable? J Econ Behav Organ 8(1):121-136

Gerlach K, Jirjahn U (2001) Employer provided further training: evidence from German establishment data. Schmollers Jahr 121(2):139-164

Greenhalgh C (2002) Does an employer training levy work? The incidence of and returns to adult vocational training in France and Britain. Fiscal studies 23(2):223-263

Hashimoto M (1981) Firm-specific human capital as a shared investment. Am Econ Rev 71(3):475-482

Kamphuis P, Glebbeek AC, Van Lieshout H (2010) Do sectoral training funds stimulate training? Int J Train Dev 14 (4):273-290

Krueger A, Rouse C (1998) The effect of workplace education on earnings, turnover, and job performance. J Labor Econ 16(1):61-94

Lakies T (2012) Weiterbildung und Rückzahlungsklauseln. Berufsbildung in Wissenschaft und Praxis 41(1):49-51

Leuven E (2005) The economics of private sector training: a survey of the literature. J Econ Surv 19(1):91-111

Lynch LM, Black SE (1998) Beyond the incidence of employer-provided training. Ind Labor Relat Rev 52(1):64-81

Muehlemann S, Wolter SC (2006) Regional Effects on Employer Provided Training: Evidence From Apprenticeship in Switzerland. CESifo Working Paper 1665, Munich

Muehlemann S, Wolter SC (2011) Firm-sponsored training and poaching externalities in regional labor markets. Reg Sci Urban Econ 41:560-570

Mueller N (2012) Weiterbildung und Belegschaftsfluktuation in deutschen Betrieben. WSI Mitteilungen 65(5):365-373

Mueller N (2013a) Abschlussbericht zum Projekt „Berufliche Weiterbildung: Ursachen möglicher Unterinvestitionen und Anreize für Betriebe und Beschäftigte" - Teil 3: Fluktuation und betriebliche Weiterbildung (BIBB-FluCT-Erhebung), Bundesinstitut für Berufsbildung. Bundesinstitut für Berufsbildung (BIBB), Bonn, http://www.bibb.de/de/wlk54493.htm

Mueller N (2013b) Staff Fluctuation and Employer-Provided Continuing Training (FluCT) 2011 gwa_1.0; Forschungsdatenzentrum im BIBB (ed., data access). Bundesinstitut für Berufsbildung, Bonn: , doi:10.7803/678.11.1.2.10

Mueller N (2013c) Unterinvestieren Betriebe in berufliche Weiterbildung? REPORT. Zeitschrift für Weiterbildungsforschung 2(36):13-28 
Neubaeumer R, Kohaut S, Seidenspinner M (2006) Determinanten betrieblicher Weiterbildung - ein ganzheitlicher Ansatz zur Erklärung des betrieblichen Weiterbildungsverhaltens und eine empirische Analyse für Westdeutschland. Schmollers Jahr 126:437-471

OECD (2003) Beyond Rhetoric: Adult Learning Policies and Practices. OECD, Paris

OECD (2004) Co-Financing Lifelong Learning - Towards a Systemic Approach. Paris

Pigou AC (1912) Wealth and Welfare. Macmillan and Co., London

Stevens M (1994) A theoretical model of on-the-job-training with Imperfect competition. Oxf Econ Pap 46(4):537-562 Stevens M (1996) Transferable training and poaching externalities. In: Booth AL, Snower DJ (eds) Acquiring skills - Market failures, their symptoms and policy responses. Cambridge University Press, Cambridge, pp 19-40

Stevens M (2001) Should firms be required to pay for training? Econ J 111:485-505, doi: 10.1111/1468-0297.00647

Wooldridge JM (2009) Introductory Econometrics, 4th edn. Mason, Mason, $\mathrm{OH}$

Zweimueller J, Winter-Ebmer R (2003) On-the-job-training, job search and job mobility. Schweizerische Zeitschrift für Volkswirtschaft und Statistik 139(4):563-576

doi:10.1186/1877-6345-6-1

Cite this article as: Mueller: Does CVT of firms in Germany suffer from poaching? Empirical Research in Vocational Education and Training 2014 6:1.

Submit your manuscript to a SpringerOpen ${ }^{\circ}$ journal and benefit from:

- Convenient online submission

- Rigorous peer review

- Immediate publication on acceptance

- Open access: articles freely available online

- High visibility within the field

Retaining the copyright to your article 